\title{
META-ANALYSIS: EFFECT OF SCREEN TIME ON OBESITY IN CHILDREN AND ADOLESCENTS
}

\author{
Salwa Annisaa'), Yulia Lanti Retno Dewi²), Eti Poncorini Pamungkasari2) \\ ${ }^{1)}$ Masters Program in Public Health, Universitas Sebelas Maret \\ ${ }^{2)}$ Faculty of Medicine, Universitas Sebelas Maret
}

\begin{abstract}
Background: A number of observational studies and rigorous experimental trials tested the effects of reducing children's screen media exposure on weight gain. Current evidence suggests that screen media exposure leads to obesity in children and adolescents through increased eating while viewing (exposure to high-calorie, lownutrient food and beverage marketing that influences children's preferences, purchase requests, consumption habits) and reduced sleep duration. This study was conducted to investigate the effect of screen time on obesity in children and adolescents.

Subjects and Method: This was a systematic review and meta-analysis. The study was conducted in multiple databases including PubMed, Science Direct, Google Scholar, Springerlink, and complemented by cross-referencing to identify randomized control trial published from 2011 to 2021. The following search terms were used: obesity OR obese OR overweight AND "fast foods" OR snacks OR "fried foods" AND "social media" OR "screen time" OR television AND child OR adolescent. The inclusion criteria were full text, cross-sectional study, and reported adjusted odds ratio (aOR). The articles were filtered using PICO model, including: (1) Population= children and adolescents, (2) intervention $=$ screen time $\geq 3$ hours, (3) comparison $=$ screen time $<3$ hours, and (4) outcome= obesity. The inclusion criteria were English full-text and reported mean and standard deviation. The systematic review was carried out according to the PRISMA flow diagram. Data analysis were performed using RevMan 5.3.

Results: 11 eligible articles from Ethiopia, Italy, Tanzania, China, Canada, Saudi Arabia, Nepal, and Pakistan were included for meta analysis. This study showed that screen time $\geq 3$ hours elevated the risk of obesity in children and adolescents 1.40 times than screen time $<3$ hours $(\mathrm{aOR}=1.40 ; 95 \% \mathrm{CI}=1.21$ to $1.62 ; \mathrm{p}=0.001)$.
\end{abstract}

Conclusion: Screen time $\geq 3$ hours elevates the risk of obesity in children and adolescents 1.40 times than screen time $<3$ hours.

Keywords: obesity, screen time, children, adolescents

\section{Correspondence:s}

Salwa Annisaa. Masters Program in Public Health, Universitas Sebelas Maret. Jl. Ir. Sutami 36A, Surakarta 57126, Central Java. Email: salwaannisaa@student.uns.ac.id. Mobile: 081541180488. 